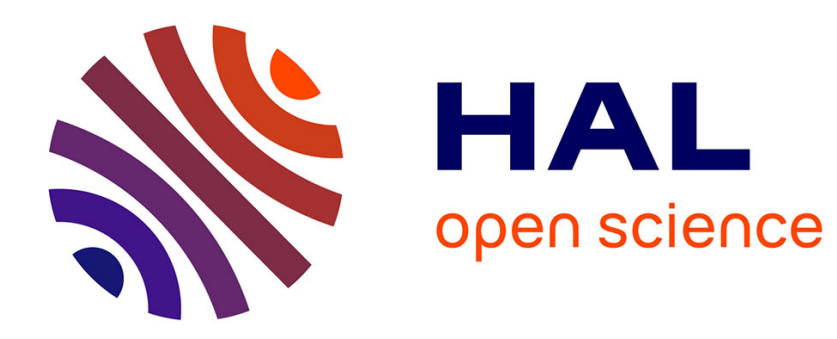

\title{
Mapping innovation dynamics in hospitals
}

Faridah Djellal, Faïz Gallouj

\section{- To cite this version:}

Faridah Djellal, Faïz Gallouj. Mapping innovation dynamics in hospitals. Research Policy, 2005, 34, pp.817-835. halshs-01133749

\section{HAL Id: halshs-01133749 \\ https://shs.hal.science/halshs-01133749}

Submitted on 20 Mar 2015

HAL is a multi-disciplinary open access archive for the deposit and dissemination of scientific research documents, whether they are published or not. The documents may come from teaching and research institutions in France or abroad, or from public or private research centers.
L'archive ouverte pluridisciplinaire HAL, est destinée au dépôt et à la diffusion de documents scientifiques de niveau recherche, publiés ou non, émanant des établissements d'enseignement et de recherche français ou étrangers, des laboratoires publics ou privés. 


\title{
Mapping Innovation Dynamics in Hospitals ${ }^{1}$
}

\author{
Faridah Djellal and Faïz Gallouj \\ Clersé, University of Lille 1 and Ifrési-CNRS, Lille, France
}

\author{
(Published in Research Policy: DJELLAL F., GALLOUJ F., (2005), Mapping \\ innovation dynamics in hospitals, Research Policy, Vol. 34, p. 817-835.)
}

\begin{abstract}
This article draws on a notion of the hospital as a complex service provider and healthcare system hub in order to examine the question of innovation in hospitals. It puts forward a relatively simple framework for analysing hospital output, in which the medical function is incorporated into a complex system of other constituent services that make use of different types of technologies. This analytical framework is used to reveal the multiple sources of innovation and the main organising principles driving innovation within hospitals.
\end{abstract}

Keywords : Innovation; Hospitals; Service sector

\section{Introduction}

The economic literature has long stigmatised service activities and, in so doing, has frequently made metaphorical use of medical terminology. Thus such activities, it is alleged, not only suffer from certain more or less serious pathologies (cost disease, Solow's syndrome, etc.) but they also weaken and thereby endanger manufacturing industries, the vital organs of the economic system, the only true wealth creators and the only genuine source of innovation in the economy.

There is a sense in which hospitals are not included in this diagnosis. In particuliar, the association of the words innovation and hospital does not seem incongruous. Within the service sector as a whole, hospital services, and indeed medical services in general, occupy a particular position, to the extent that nobody disputes either their social usefulness, their symbolic importance (relationship to life and death) and prestige, or their capacity for research and innovation. On the contrary. However, we hyothesise that the innovation effort in hospitals is underestimated or even, in some cases, wholly unrecognised. This is all the more true the further one moves from the traditional scientific activities that produce medical innovations (whether of process or product) using a strong 'science-push' approach.

\footnotetext{
${ }^{1}$ This article draws on a research carried out for the Department of Research, Evaluation and Statistics (DREES) of the French ministries of Social Affairs, Work and Solidarity and of Health, the Family and the Handicapped. It is based, firstly, on extended interviews conducted in several hospitals and their health authorities and, secondly, on a secondary analysis of empirical material found in the specialist literature.
} 
The aim of this paper is to develop a general analytical framework that should make it possible to understand innovation in hospitals in all its diversity.

In view of its principal objective, which is to develop as comprehensive a framework as possible for identifying innovation, our article necessarily adopts a broad and open definition of innovation. This decision is reflected both in the nature of the innovations taken into account (organisational, technological, product and service innovations, etc.) and in the degree of novelty those innovations display (radical innovations are included, of course, but so are minor or incremental innovations possibly resulting from a simple adaptation or change). Thus innovation is considered subjectively, with the element of novelty being apprehended in relative rather than absolute terms. It is also considered extensively in order to encompass both innovations generated internally and those originating externally, that is those adopted from outside sources.

The paper is divided into three sections. The first section is given over to a rapid survey of the literature on innovation in hospitals. This literature can be said to be dominated by what we call technologist approaches, that is approaches that focus on the introduction of technological systems, initially medical technological systems and then increasingly also management technological systems (particularly computerbased ones). In section 2, we develop a framework for analysing the provision of hospital services, which is conceived as the provision of a complex service in which the medical function as such is integrated into a complex system of other constituent services. The quality and dynamic (in the sense of aptitude for innovation) of these services has significant effects on the efficiency of medical services proper. The general 'morphology' of hospital services outlined in section 2 provides a basis for the construction, in section 3, of a typology of the organising principles driving innovation in hospitals. This typology is illustrated with a number of concrete examples.

\section{The literature on innovation in hospitals}

The literature on innovation in hospitals can be divided into four groups of uneven size, with each group adopting a different approach to the question.

The first group, in which hospitals are broadly likened to firms, favours an approach in which hospitals are conceived as production functions. The second group adopts an approach in which a hospital is seen as a 'set of technological and biopharmacological capacities'. This group of studies is extremely heterogeneous in terms of the disciplines involved and the theoretical approaches adopted. The characteristic they all share is that they emphasise what we will call medical innovation, a term we use as a generic appellation for various types of (tangible and intangible) technological and bio-pharmacological innovations in the healthcare field. The third group comprises an increasingly large number of studies that consider hospitals as 'data-processing machines' and address the question of innovation in hospitals from the perspective of the introduction of information systems. In the fourth and final group, which is the most recent and probably the least voluminous, hospitals are seen as providers of complex services and healthcare system hubs. In this approach, hospitals are regarded as combinative providers of diverse and dynamic services, able to go beyond their own institutional boundaries by becoming part of 
larger networks of healthcare provision, which are themselves diverse and dynamic (inter-hospital agreements on the shared use of equipment, community health networks set up to tackle a range of pathologies or even social problems). This approach makes it possible to extend the model of hospital innovation to incorporate new forms of innovation and new actors in the innovation process, in accordance with the Schumpeterian tradition of openness (Schumpeter, 1934).

We do not claim to be undertaking a comprehensive survey here since, as we noted in the introduction, the literature on innovation in hospitals is particularly extensive. However, the four groups identified by the proposed synthetic interpretative framework seem to us capable of taking account of this literature satisfactorily. We have not attempted systematically to quantify the four groups in question, whether at national or international level. Nevertheless, the last group seems to be the least dense in terms of references (particularly theoretical ones).

\subsection{Hospital as a production function}

Under the impetus of Arrow's seminal study (Arrow, 1963), the discipline of health economics developed initially by borrowing the tools of standard economic theory. Thus hospitals were likened to standard firms and represented by production functions. Phelps (1992), for example, takes the view that there is not the slightest difference between the production of motor vehicles and the production of health. In both cases, factors of production (steel, plastic, labour etc, in the case of motor vehicles and 'medical care' in the case of health) are combined to create a product.

Thus the production function for healthcare can be written as follows: $H=g(m)$, in which $\mathrm{H}$ denotes the product 'health' and $\mathrm{m}$ 'medical care', that is a set of activities intended to restore or increase an individual's health capital. The marginal productivity of medical care is assumed to be positive and the returns to scale declining.

Medical care (m), which is described here as a homogeneous activity, is in fact made up of a large number of variables: capital (beds, diagnostic and therapeutic equipment, operating theatres etc.), supplies (bed sheets, more or less sophisticated drugs etc.), different types of workers (nurses, doctors, secretaries, administrators etc.) and patients, since they are themselves participants in the provision of healthcare (coproduction). Similarly, the product $(\mathrm{H})$ is not homogeneous, since 'hospitals and medical practices are like multi-task workshops producing a varied range of products, each of which is specially tailored to a particular patient' (Phelps, 1992). Thus this production model does not differ in essence from that of organisations such as hairdressing salons, car and electrical equipment repair shops and grocery stores. In order to take account of these heterogeneous inputs and outputs, a hospital's production function could be written as follows: $\left(\mathrm{H}_{1}, \mathrm{H}_{2}, \ldots \mathrm{H}_{\mathrm{i}} \ldots \mathrm{H}_{\mathrm{m}}\right)=\mathrm{g}\left(\mathrm{m}_{1}, \mathrm{~m}_{2}, \ldots\right.$ $\left.m_{j} \ldots m_{n}\right)$.

The notion of technique lies at the heart of the concept of production function of course, to the extent that technique is defined as a given combination of production factors (here methods of healthcare). Changes in technique are explained by a change in the relative price of these factors; they are reflected in a shift along the production function. From a dynamic perspective, therefore, a hospital's production function: $\mathrm{H}_{\mathrm{t}}$ 
$=g_{t}\left(m_{t}\right)$ reflects technological change. This technological change takes the form of a shift in the production function, which expresses the notion that more 'health' $(\mathrm{H})$ is produced with the same volumes of production factors, that is 'medical care' (m), or that the same volume of health is produced with less care.

The literature on the hospital as a production function, and more specifically on the microeconomics of technical change and innovation in hospitals, is relatively extensive (Shephard, 1970; Newhouse, 1970; Conrad and Strauss, 1983; Ahern, 1999 etc.). As Béjean and Gadreau (1991) note, this standard approach to hospitals (and the producer-consumer model associated with it) emphasises the search for the optimum by relying on the definition of the rules governing public enterprise pricing. When applied to service activities, this approach also comes up against the traditional hypotheses relating to nomenclature, product anonymity and non-interaction. Some studies have sought to critique or adapt the notion of the hospital as a firm or production function. These studies have drawn in particular on the economics of bureaucracy, agency theory, convention theory and the new industrial economics (for a survey, see Béjean and Gadreau, 1991; Piatecki and Ulmann, 1995).

\subsection{A hospital as a set of technological and bio-pharmacological capacities}

The second group of studies is extremely diverse in terms of the disciplines involved and the theoretical approaches adopted within each discipline, as well as the theoretical claims made. The common factor in all these studies is that they emphasise what we will call medical innovation, which will serve as a generic appellation for various types of (tangible and intangible) technological and bio-pharmacological innovations in the field of healthcare. These studies adopt an approach in which a hospital is seen as what we propose calling 'a set of technological and biopharmacological capacities'.

Within the generic category that we call medical innovation, the following three subgroups can be identified:

1) biomedical or bio-pharmacological innovation (new medicines, new chemical or pharmaceutical substances, etc);

(2) tangible or 'hard' medical innovation, that is the introduction of technological systems for providing healthcare and biological analysis, whether they involve capital goods (e.g. MRI, scanners, etc.), miscellaneous small items of equipment (e.g. dressing kits, syringe drivers, catgut, reabsorbable prostheses, ...) or diagnostic or therapeutic equipment;

3) intangible or 'soft' medical innovation, which includes what might be called the 'invisible' technologies, that is care protocols, diagnostic or therapeutic strategies, etc.

This literature is concerned mainly with the following topics :

- the nature of medical innovation as captured through case studies and the development of more or less sophisticated typologies (Thomas, 1975 ; Schrayer, 1995 ; Groenewegen and Hutten, 1989);

- the dynamic of medical innovation, which is approached through the diffusion of medical innovation, its life cycle and its diminishing returns, the nature of the technological trajectory pursued and the constraints on medical innovation (Coleman et al., 1966 ; Geenwald et al., 1984 ; Evans, 1986 ; Eddy, 1990; Weisbrod, 1991 ; Moatti, 1996 ; Paraponaris et al. 1997, Battista, 1989; Nystrom et al., 2002 ; Jerome- 
D'Emilia and Begun, 2005);

- the impacts of medical innovation, considered in relation to a multitude of potential targets: the quality of the product (i.e. health), productivity, work organisation, the nature of the work in question, health expenditure, externalities, etc. (De Kervasdoué and Lacronique, 1981 ; Perry, 1988 ; Newhouse, 1992 ; Fuchs, 1996).

\subsection{Hospitals as information systems}

In the literature, innovation in services is very often reduced to the introduction of new information and communication technologies (NICT) (F. Gallouj, 1994 ; C. and F. Gallouj, 1996). It is true that services have, for several decades now, been the main users of such technologies. And hospitals are of course no more immune than any other service activity to the large-scale diffusion of NICTs that is the inevitable consequence of the new informational paradigm. Expenditure on information technologies in healthcare establishments has grown continuously. According to some estimates, between 40 and $60 \%$ of hospital personnel's time is given over to information processing tasks (cf. Sachot, 1989). Thus in a significant number of studies, hospitals are seen as information systems, with innovation in hospitals being considered in terms of its relations with the informational paradigm.

In surveying this literature on innovation in hospitals and its relations with NICTs, a distinction has to be made (however artificial that distinction may be in some cases) between management IT (whose object is informational and material flows) and medical IT. It was hospital administration that was first affected by computerisation. After all, information technology first began to overrun administrative departments in the mid-1960s. It was only later that it was introduced into logistical departments and then into medico-technical departments (Acker, 1995 ; Hémidy, 1996 ; Dent, 1996 ; Berbain et Minvielle, 2001 ; England et al., 2000). Medical IT now has a wide set of applications ranging from medical and patient care records to sophisticated imaging and remote network access for multiple purposes (training, diagnosis, etc.).

The favoured topics in this literature are generally the same as in the literature that adopts the 'hospital as a set of technical and bio-pharmacological capacities' approach. They include the nature of innovation (with a particular distinction being made between hybrid medical technologies and the NICTs that make remote diagnosis and treatment possible) and the diffusion of IT and its impact on the quality of healthcare and on well-being, job quality, skills and productivity (Stanback, 1987 ; Herbst et al., 1989 ; Fuchs, 1990 ; Anderson et Aydin, 1997 ; Hebert, 1998 ; Lau et al, 1998 ; Rigby, 1999 ; Dixon, 1999 ; Burke and Menachemi, 2004).

\subsection{Hospitals as service providers and healthcare system hubs}

This concept of the hospital reflects a shift of perspective away from the technicist approach towards an approach to innovation based on service and the (internal and external) service relationship. Patients are not simply sick people in need of treatment but also customers of a complex service-providing organisation that has to make every effort to satisfy not only the customers themselves but also their family and relatives.

Thus innovation in hospitals is not a black box (hospital seen in terms of its 
production function). Nor is it any longer simply the sum of more or less highly developed and spectacular medical technologies designed and/or used by a medical aristocracy (the hospital as a set of technical and bio-pharmacological capacities). And nor can it be reduced to a sophisticated and tentacular information system (hospitals as information systems).

If innovation in hospitals is to be apprehended in its totality, it is necessary to break into the black box of the organisation, a task to which disciplines such as sociology, socio-economics or management are better suited than economics itself. Penetrating the black box in this way puts the spotlight on the actors in innovation and on support functions (hotels, catering, laundering, transport, etc.) that are also neglected. This underestimation of hospitals' non-medical functions is widespread and does not apply simply to matters related to innovation. For example, there is relatively little literature on the working conditions, competences and responsibilities of non-medical hospital staff, whereas the literature on these topics as they concern medical staff is extensive (Griffin-Cohen, 2001).

It is this approach that we would like to adopt in the rest of this article. In our experience, the specialist professional literature is less resistant to adopting an approach that is open to the multiple aspects of innovation in hospitals. This observation is yet another indication that theoretical thinking frequently lags behind the concerns of professionals.

To conclude this rapid survey (for a more comprehensive survey see Djellal et al., 2004), we can say that approaches to innovation in hospitals suffer from a twofold inadequacy: 1) for the most part, they favour a scientific and technological approach to innovation (the first three groups outlined above), and 2) they favour an approach to innovation that focuses disproportionately on healthcare activities themselves (diagnosis and treatment) to the detriment of other service activities that are often described as 'peripheral'.

\section{A functional breakdown of hospital output}

In theoretical terms, the analytical framework proposed here draws on some of the findings of the economics of services (Hill, 1977, 1999 ; Gadrey, 1996, 2000) and of the economics of innovation (Gallouj and Weinstein, 1997 ; Gallouj, 2002), which it seeks to reconcile and render more operational in order to consider the question of innovation in more concrete terms.

In the framework put forward here, the 'product' (service) is considered in a less abstract manner than in the definitions given by Hill (1999) or Gadrey (2000) ${ }^{2}$ or in the Lancasterian notion of a service (defined in terms of characteristics) put forward by Gallouj and Weinstein (1997). Thus our framework is adapted to the output of hospitals while nevertheless retaining certain theoretical ambitions.

The delivery of hospital services is a complex activity that can be captured in its totality by linking four variables (cf. Table 1):

\footnotetext{
${ }^{2}$ In both these cases, services are defined as the process by which a medium is transformed by a service provider on behalf of a client.
} 
1) the constituent services $\left(\mathrm{S}_{\mathrm{i}}\right)$ that make up total hospital output;

2) the mediums or targets of service provision;

3) the service characteristics or utilities achieved or sought;

4) the competences of the service providers.

\subsection{The constituent services $\left(S_{i}\right)$}

Of course, the 'primary' or 'basic hospital service' is made up of the medical treatment (or nursing care) itself. However, hospital services cannot be reduced to such treatment or care. The constituent services that make up a hospital's output are generally divided into three groups: 1) services of the hotel/catering type, 2) administrative and managerial services and 3) medical and paramedical services. In reality, however, there are other constituent services that fall outside these three components of hospital services. These might include, by way of example, the various retail activities (shops) located within hospitals, recreational activities, beauty treatments and childminding services. Thus in addressing issues relating to innovation, it is necessary not to be locked into rigid typologies.

\subsection{The principal medium of service delivery}

In accordance with the notion of the service triangle (Gadrey 1996), the principal medium of service delivery may be material objects (M), information (I), knowledge $(\mathrm{K})$ or individuals $(\mathrm{R})$. These various mediums are associated with the basic functions or groups of operations as well as with particular families of technologies.

Thus four groups of operations can be identified (Gadrey, 1991 ; Gallouj, 1999) :

- logistical and material transformation operations (M), which involve the processing of tangible objects, that is transporting, transforming, maintaining or repairing them;

- logistical and information processing operations (I), which involve the gathering and processing of codified information, that is producing, capturing, transporting, archiving and updating it;

- operations involving the intellectual processing of knowledge $(\mathrm{K})$ using codified methods and routines and intangible technologies;

- contactual or relational service operations (R), in which the principal medium is the customer and which consist of a direct service provided in contact with the customer and with a greater or lesser degree of interaction.

Each constituent service $\left(\mathrm{S}_{\mathrm{i}}\right)$ combines these various groups of operations in differing proportions (depending on the hospital and time in question).

These four groups of operations can also be associated with scientific and technological groups. Thus the functional breakdown of output can also be envisaged as a scientific and technological breakdown. The first three groups of operations correspond, respectively, to material processing technologies (robotics, mechanics etc.), information processing technologies (computers, telecommunications, imaging etc.) and knowledge processing technologies (intangible technologies, methods of diagnosis and treatment etc.) as well as, in each of these cases, to the corresponding scientific and technological disciplines. The component $\mathrm{R}$ (relational operations) 
occupies a special position, in the sense that the sciences and technologies used in processing relations or direct services may borrow from each of the preceding disciplines and from others, particularly the human and social sciences.

\subsection{The basic service characteristics or use values $(Y)$}

These characteristics are located 'downstream' of our breakdown of output. They describe the utilities derived from the deployment, during the various types of operations that make up the service provision, of the internal technical components and/or competences.

These utilities or service characteristics (Y) should not be confused with the constituent services $\left(\mathrm{S}_{\mathrm{i}}\right)$. Thus each constituent service $\mathrm{S}_{\mathrm{i}}$ mobilises different competences and technologies in order to carry out a variable number of processing operations on different mediums. These competences, technologies and activities, taken as a whole, contribute to the production of utilities for the customer (healing or cure, for example, in the case of the constituent service 'treatment'; cleanliness in the case of the constituent service 'cleaning').

These service characteristics are considered from the point of view of the user. In service activities, in contrast to goods, the task of identifying and labelling them may vary in difficulty depending on the type of constituent service in question. However that may be, the theoretical relevance of this category cannot be challenged, since services provide services in just the same way as goods do.

If the hospital service as a whole is adopted as the unit of analysis, then it can be defined as a 'package' type of service. In this case, a simple way of denoting the service characteristics is to represent them in terms of the various constituent services or functions that make up the package (hotel/accommodation services, transport, retail activities, etc.). Thus each constituent service is assumed to denote the corresponding (abstract and unspecified) constituent function. In reality, however, hospitals are 'packages of packages', in the sense that each constituent service or service function may in turn be represented by a vector of service characteristics. Thus the constituent function 'retail activities' may have the following service characteristics: product range, choice, extent of opening hours, level of service, etc. The treatment function has characteristics such as healing, level of sequelae, information provided, etc. Unintentional service functions or characteristics, that is perverse effects or negative externalities, could be added to these (desired) service functions or characteristics. They might include, for example, the contraction of nosocomial diseases.

\subsection{The service providers' competences $(C)$}

The service providers' competences relate here to individuals (doctors, nurses, cooks, secretaries etc.) or to small groups (the team or teams involved in delivery of the service). These competences are derived from various sources: initial education and training, continuing training, experience and, more generally, the various interactions that are sources of learning. They may be recognised by a professional body or another system of qualification verification. The nature and form of these competences may be codified, that is they can be reduced to messages that can be diffused at zero cost (Foray, 1994). However, they are also frequently tacit, that is 
only weakly articulated, difficult to transfer and indissociable from the individuals in whom they are embodied. Whether codified or tacit, these competences can be roughly divided into several types:

- scientific and technical competences (cognitive or professional competences);

- internal and external relational competences (depending on whether the relations are internal to the team or with the customer and the others involved in delivering treatment);

- combinatory or creative competences (i.e. ability to combine technical characteristics in coherent sets or subsets);

- (manual) operational competences, such as those at the heart of logistical functions (maintenance, catering, laundering etc.), or, to take a completely different example, those required for surgical functions.

These competences are located 'upstream' of our breakdown of hospital output. They may be competences in the technologies deployed and the various types of operations carried out or they may be competences that are directly mobilised, without any technical mediation, in order to produce utilities (Y). In this latter case, the service can be represented by the following heuristic formula: $C(Y)$, which denotes, as it were, a 'pure service' situation.

Depending on the constituent service under consideration and hence on the type of service provider, these competences may be extremely diverse, particularly in terms of their scientific and technical components. Just like the preceding variable (i.e. utility), competences are characteristics that are difficult to identify and label. The degree of difficulty varies depending on the constituent service and type of service provider being considered.

Thus Table 1 provides a relatively simple representation of 'hospital output' in all its functional and technological diversity. That hospital output can be represented simply as the aggregate of various types of constituent services $\left(\mathrm{S}_{\mathrm{i}}\right)$. Each of these $\mathrm{S}_{\mathrm{i}}$ can itself be seen as the combination, to varying degrees, of basic operations carried out on objects, information, knowledge or individuals. In other words, the table's various columns, the variables $\mathrm{C}, \mathrm{Y}$ and the group (M, I, K and R) are not located at the same level of analysis. After all, M, I, K and R are 'internal' functions or components of the hospital output, whereas $\mathrm{C}$ is located upstream of service delivery and $\mathrm{Y}$ is located downstream of it (we are dealing here with external functions). This means that the competences play a part in the implementation of the corresponding operations and technologies, which in turn are translated into the provision of service characteristics.

\section{INSERT Table 1 : a functional breakdown of hospital output or service}

\subsection{Hospital output: an internal and external extension of the analytical framework}

The framework for analysing hospital output just outlined above refers to hospitals in their totality, that is all the units (departments, functions, etc.) of which it is made up (organisational or institutional level). However, other perspectives are possible and, as we shall see, they are likely to enrich our analysis of innovation in hospitals. We refer here to the intra-organisational and inter-organisational levels. 
We should not be misled by the representation of hospital output, particularly not as far as the constituent services $S_{i}$ are concerned. After all, each hospital is a 'package of packages' of constituent services. Each $\mathrm{S}_{\mathrm{i}}$ (whether it be medical services, accommodation services, catering services, etc.) can itself be broken down into a set of constituent services $\mathrm{s}_{\mathrm{ij}}$, which could constitute independent units of analysis.

Thus the provision of the generic constituent service denoted by the label 'medical treatment/nursing care' $\left(\mathrm{S}_{\mathrm{i}}\right)$ can be regarded as a package of constituent services $\left(\mathrm{s}_{\mathrm{ij}}\right)$, which might include, for example, treatment and care, tests, radiology, surgery, rehabilitation, anaesthetics, consultations, etc. Similarly, the generic constituent service 'retail activities' could be broken down into other constituent services : florists, gift shops, etc.

The inter-organisational level, for its part, takes account of a hospital's integration into the external environment. This integration is mediated through stronger relations with the system of which it is itself a part (healthcare system) and with other systems outside the field of healthcare (manufacturers, suppliers, providers of various services, etc.).

Thus hospitals are increasingly opening up to their environment and are becoming one element among others in healthcare systems. They cultivate links with doctors in private practice, other hospitals and/or clinics etc. in order to build up healthcare networks (Béjean and Gadreau, 1997 ; Delande, 1999 ; Costargent, 2000 ; Billard, 2001 ; Larcher and Poloméni, 2001).

This involvement in the external environment is not confined to the world of healthcare. Hospitals are tending to develop various forms of partnerships, including with private organisations. Thus an increasing number of hospitals are making use of sponsoring techniques and calling on the services of various consultants. Some are also starting to sell non-medical services (catering, laundry, software etc.) to other hospitals as well as to other economic agents, both public and private.

Table 2 depicts our output analysis framework when it is extended to encompass the inter-organisational level. Quite simply, this new framework consists of a given hospital (whose output is defined by a more or less complex aggregation of constituent services, technologies and competences) that is linked to other organisations $^{3}$ (defined by the same elements), which may be, as we have already said, more or less sophisticated healthcare organisations or any other type of organisation apart from those involved in healthcare. This widens the scope of hospital output and, as we shall see in the next section, brings more potential sources of innovation into play.

\section{INSERT Table 2 : The inter-organisational level of analysis of hospital output}

The general analytical framework outlined in Table 1, together with its internal and external extensions (Table 2), seem to us to be useful tools, firstly for undertaking detailed analyses of the various aspects of a hospital's output and then for considering in a structured and systematic way the question of how that output evolves and is

\footnotetext{
${ }^{3}$ The hospital may also be linked with individuals or individual entrepreneurs.
} 
transformed, that is the question of innovation.

\section{A framework for analysing innovation in hospitals}

The general representation of hospital output outlined above constitutes an attempt to break into the ' black box' of hospital activity. It captures not only a hospital's end product but also all its intermediate products as well as products developed on the boundary between the hospital and its environment, that is in collaboration with external actors. It has the capacity to provide us with a general framework for analysing innovation in hospitals.

Use of this framework will reveal, analytically, the diversity of forms of innovation that exist in hospitals. This diversity is all the greater since, as we have already suggested, hospital output (and hence innovation) can be analysed at several different levels, namely the organisational, intra-organisational and inter-organisational levels. However, over and above the extreme diversity of types of innovation, the framework can also be used to highlight a limited number of organising principles driving innovation in hospitals. As we shall see, these organising principles can be described as extensive, regressive, intensive and combinatory. Before defining in more precise terms the content of each of these organising principles, we need to examine the way in which our analytical framework takes account of the various approaches to innovation in hospitals considered in section 1 above.

\subsection{The analytical framework and the various approches to innovation in hospitals}

Our framework for analysing hospital output can be used to locate, within the functional and technological space, the main approaches to innovation in hospitals outlined in our literature review.

If we begin by examining the framework row by row, it is clear that the bulk of the existing literature on innovation in hospitals is located in row $\mathrm{S}_{1}$ (cf. Table 1). The focus of this literature is the constituent service 'medical treatment/care', which of course constitutes a hospital's core activity. If we now examine the framework column by column, it is clear that the literature focuses either on column $\mathrm{M}$, that is on the technologies associated with material operations, including those involving living matter (biomedical innovations, new technological equipment, etc.), or on column I, that is on the technologies associated with information processing operations, that is the new information and communications technologies. Thus, as was already noted in section 1, the main focus of attention of most studies and research on innovation in hospitals lies at the intersection between columns $\mathrm{M}$ and $\mathrm{I}$, on the one hand, and row $\mathrm{S}_{1}$, on the other. Thus a row-by-row reading of our literature survey (represented by the shaded area in Table 1) reflects this literature's 'functional' deficit or atrophy, while a column-by-column reading shows its technological bias. The predominant approaches are those that view hospitals as production functions, as sets of technical and bio-pharmacological capacities and as information systems.

For its part, our analytical framework adopts an approach in which, whatever the level of analysis, hospitals are regarded as complex service providers that are architectural in nature. Our hypothesis is that, in order to capture innovation in hospitals in its entirety, not only should no row or column of the table be neglected but it should also 
be accepted that rows might have to be added (or, in some cases, removed).

\subsection{The extensive organising principle}

At the organisational level of analysis, the extensive organising principle will lead to rows being added to the table (all other things being equal). In other words, constituent services $\left(\mathrm{S}_{\mathrm{i}}\right)$ are added to the core service or, more generally, to the existing service (which is a combination of core and peripheral services).

The extensive principle is encountered very frequently in 'package'-type services such as the hotel trade or distribution (C. Gallouj, 1997). However, it can also be seen at work in other categories of service activities, such as operational services or certain consultancy activities. In the case of hospitals, the core service is made up of nursing or medical services. Services such as accommodation, transport, catering, etc. are peripheral services whose purpose is to complement the core service or to facilitate access to it, although they are not in themselves the reason why customers or users would go to a hospital. Be that as it may, the addition of peripheral services to the core service(s) can be regarded as falling within the scope of the extensive principle.

To some extent, this extensive model of innovation comes within the framework of certain types of differentiation strategies, and in particular of so-called improvement strategies, which involve considerable enhancement of the service provision in question by the addition of new characteristics that are valued by customers or users. Extending the range of specialities and services on offer and competing on the range of services provided seem to be important elements in hospitals' strategies.

The constituent services thus added may, in theory, be drawn from any of the major groups of hospital services already identified: 1) medical and paramedical services; 2) services of the accommodation, catering or retailing type; 3) managerial or administrative services. As has already been noted, attempts to innovate within hospitals (as well as the research on innovation carried out by social scientists) tends to focus on the first group at the expense of the others. However, the other groups' potential for expressing extensive innovation is very considerable. It should not be ignored, just as we should not ignore the opportunities for innovation offered by other categories of services (leisure activities, recreation, etc.).

A particularly large number of innovations fall within the scope of this extensive organising principle. Limiting ourselves to non-medical services, the following examples can be cited:

- The opening of hotels or family houses in hospitals for patients receiving outpatient treatment and/or their families.

- The introduction of various forms of hospital retailing. Swindley and Thompson (1992) cite the following examples: bookshops, gift shops, mini-supermarkets, florists, toy shops, banks, shoe repairers, dry cleaners, travel agencies, legal advice units, photographers, hairdressers, pharmacies, postal services, sweetshops, health food stores etc.

- The provision of restaurants for in-patients and their families.

- The provision of luxury hospital suites. 
- The establishment of management control, communications and quality assurance departments.

- The organisation of recreational activities for children in hospital and the establishment of fitness centres.

- The introduction of childcare services.

- The provision of taxi services for people who have been drinking.

- The provision of classes in various fields ranging from preventive medicine to more unconventional fields such as bicycle repairs, dancing, clowning and coping with divorce (Sasaki, 2003).

A shift of analytical perspective considerably extends the boundaries of the extensive model of innovation. Thus it becomes possible to consider the addition not only of new generic services $S_{i}$ but also, within each of these generic services, of constituent services $s_{\mathrm{ij}}$ (intra-organisational level). In other words, rather like those Russian nesting dolls, each row in the table can be regarded as a new table, which can itself have new rows added to it (extensive model of innovation). This iterative process comes to an end when the organisational units embodying the output become blurred and the constituent services are no longer defined in terms of other constituent services but rather by a set of utilities or service characteristics (Y).

From an inter-organisational perspective, an external constituent service (medical or non-medical) could be added to the output of our reference hospital, in accordance with what might be called the external extensive organising principle.

\subsection{The 'regressive' (or 'purifying') organising principle}

Our presentation separates out the regressive principle from the extensive principle. In reality, the separation is an artificial one, since these two principles are in essence very similar. In both cases, action is exerted on the rows of the table.

The principle at work here (again, irrespective of the level of analysis) involves the elimination of constituent services, that is the elimination of 'rows' from the table. In management sciences, the term 'purifying' or 'refining' strategy is used to denote this principle of effecting considerable reductions in the offer relative to a reference offer. It may seem paradoxical to link the terms innovation and regression (or purification) in this way. It is nonetheless the case that innovation processes in many service activities follow a service reduction trajectory. Hospitals are not immune to this principle.

It is more difficult to provide illustrations of this model of innovation at work in its pure form (without the intervention of other mechanisms). However, the principle might reasonably be considered to manifest itself in different ways in the following situations.

It is at work to some extent in the distinction between local hospitals and regional and/or teaching hospitals. After all, the minimal set of technical capacities provided by local hospitals may be due to the elimination of many of the constituent services provided by regional and teaching hospitals. This is the same 'minimum service' principle that is found in the fast-food industry, for example, in charter flights and in the new low-cost airlines, as well as in discount stores and budget hotel chains (e.g. 
Travelodge).

It is also at work in the establishment of highly specialised hospitals, whether their speciality is hand surgery or treatment for the foot lesions suffered by diabetics. Teboul (1999) also provides an example of innovation that falls to some extent within the scope of this regressive or purifying model of innovation. This is a private clinic that treats only one type of patient, namely those suffering from inguinal hernias. This clinic has taken specialisation (in other words, the regressive model of innovation) to such a level that it refuses to operate on, for example, obese people suffering from hernias or patients declaring a history of heart disease. Another illustration is provided by the development in the USA of the MinuteClinic concept. This is a mini doctor's surgery which, without the need to make an appointment and with a commitment to keep waiting times under 15 minutes, treats a limited number of common complaints, such as ear, bladder and sinus infections, strep throat etc.

This principle can also undoubtedly be said to be driving some of the outsourcing practices that have expanded considerably since the 1980s, particularly in logistical functions (Cubbin et al, 1987).

\subsection{The intensive organising principle}

For a given constituent service $\mathrm{S}_{\mathrm{i}}$ (medical treatment and nursing care, accommodation services, cleaning, etc.), the intensive model of innovation involves changing one of the various internal or external components of a hospital's output, either by adding new competences and/or (tangible or intangible) technologies (which may be accompanied by the elimination of old competences and/or technologies) or by increasing (or sometimes reducing) the significance (value) of existing competences and/or technologies. Thus the intensive principle manifests itself in (positive or negative) action on the 'columns' of our analytical framework. Thus the intensive organising principle finds expression in both the mobilisation (creation or adoption) of tangible or intangible innovations and the implementation of learning phenomena in various forms: learning by doing, by using, by trying, by interacting, etc. (Hatchuel, 1994 ; Boullier and De Certaines, 1992 ; Waissman, 1995, Bartoli and Anaut, 1996).

In hospitals as in other service activities (Gallouj, 1999 ; Djellal, 2002), this intensive model of innovation may follow five different trajectories for any given constituent service $S_{i}$ (intra-organisational level) or for a hospital's service provision as a whole: a logistical and material transformation trajectory, a logistical and information processing trajectory, a methodological and cognitive trajectory, a pure 'service' trajectory and, finally, a relational trajectory.

\section{4 .1 The logistical and material transformation trajectory}

This trajectory is at work in that part of the service involving logistics and material transformation. This trajectory reflects technological developments relating to the transportation and transformation of material substances, whether human or physical. It encompasses both the development of biomedical or bio-pharmacological innovations and 'tangible' medical innovations (e.g. imaging), as well as technologies for processing material substances within hospitals (transportation systems for 
individuals or equipment, cooking and refrigeration systems, cleaning systems, various kinds of dispensing machines, etc.).

This trajectory is often described as a 'natural' trajectory in Nelson and Winter's sense of the term (Nelson and Winter, 1982), based on increasing mechanisation and exploitation of economies of scale. In innovation in hospitals, however, it is only innovations related to the processing of physical matter that share these two objectives. It is rarer for the technological trajectories of innovations relating to the (medical) processing of human matter to be driven by the prospect of achieving economies of scale.

There are many examples of innovations falling within the scope of this trajectory. As far as the technologies used in the (medical) processing of human matter are concerned, they include the introduction of new technical systems or small items of equipment (e.g. the replacement of electric scalpels by ultrasonic dissectors, the use of high tech hip protector for elderly, the use of disposable, single-use items such as syringes, etc.), as well as the introduction of new drug treatments or medicines that have been optimised to improve the treatment of a given disease. As far as technologies for the (non-medical) 'processing' of physical or human matter are concerned, examples might include the design and development of motorised bedmoving equipment, the development of new cooking equipment or of new food transport systems and the introduction of a multi-functional vehicle adapted for the many different needs of hospital logistics. In the field of cleaning services, examples might include the introduction of mircrofibre technology in cleaning equipment and process, automatic cleaning robots, etc. Other examples, drawn this time from hospital laundering services, include the introduction (in their time) of automatic feeders, automatic stackers and tunnel finishers (Sachot, 1989).

\subsubsection{The logistical and information processing trajectory}

This trajectory emerges in the informational component of the service and equates, self-evidently, to the dynamic or the upgrading of information and communications systems. It is characterised in particular by a trend towards the reduction of communication costs, networking and the production of new information and of new ways of using information.

This informational trajectory is, of course, particularly important in the (constituent) services relating to the management and administration of information flows. Examples include the collection of hospital revenue at automatic payment stations ${ }^{4}$ (Viguier, 1994; Viguier et al., 1994), the development of an interactive system for use in drawing up nurses' work schedules in the various departments and clinics of a teaching hospital (Courbon, 1995) and the establishment of ultra-sophisticated processing and dispatching centres for emergency calls (Gilibert and Fabretti, 1998). However, this informational trajectory is also becoming increasingly evident in the management of material flows (stock management, kitchen management or digital kitchen, software for health waste elimination tracing, etc.) and in medical services (telemedicine, crosschecking bar codes on drugs and patients' wristbands in order to

\footnotetext{
${ }^{4}$ This trajectory is also relational.
} 
decrease medical errors, easy-to-use portable skin-screening camera for cancer detection).

\subsubsection{The methodological trajectory}

This trajectory encompasses the production and evolution of formalised methods of knowledge processing. It plays an extremely important role in knowledge-intensive services (consultancy, engineering). However, it also plays a role in some operational services, such as cleaning or transport (Djellal, 2000; 2002; Sundbo, 1996, 1998).

In the case of hospitals, these methodological trajectories are evident, once again, both in medical services and in a whole range of non-medical services. As far as medical services are concerned, these trajectories denote the development and improvement of diagnostic protocols, treatment protocols, therapeutic strategies (care maps, critical paths, practice guidelines) (Coffey, 1991 ; Hoffman, 1999 ; Lumsdon and Hagland, 1993) and hygiene protocols (including those drawn up to combat nosocomial diseases). In the field of health care for elderly, measurement and diagnostic methods constitute a particularly fertile area of research and innovation directed at a multitude of different targets: assessment of the degree of dementia, of risk (of a fall, for example), of dependency, of memory, of pain (which may be applied in different ways to different types of patients, particularly those unable to speak), the design of indicators of well-being adapted to the elderly, quality of life indicators, etc. Innovation trajectories in this sphere are driven by the following factors: the object or target of measurement, the initial level of application (local, national, international) and the degree of novelty in the method.

Turning now to non-medical services, examples falling within the scope of this trajectory would include the development of cleaning protocols adapted to the needs of hospitals (and in particular protocols for processing toxic waste), the introduction of a quality procedure among teams of stretcher bearers (Bernardy-Arbuz, Bannier, 1999), the development of measures to combat the forging of medical prescriptions (Gestions Hospitalières, 1994) or even the design of trend charts for quality and risk management (Bonhomme et al., 1994).

\subsubsection{The pure 'service' trajectory}

The service trajectory describes the implementation and evolution of service innovations that do not require any technical medium (whether tangible or intangible). Such innovations rely on the direct mobilisation of competences (C) in order to supply service functions or characteristics (Y). They may be embodied in a particular organisation and to some extent therefore they are organisational innovations (in which technical systems are not important). Thus the service trajectory falls into the category of an ideal type, since in reality the provision of a given service almost always requires the use of a technology, however rudimentary.

This service trajectory can manifest itself at any level of an organisation. However, it seems to be particularly important in front-office activities involving direct contact with customers or users (reception services, admissions, etc.). There are many examples in the literature, such as reception services targeted at specific groups, e.g. disadvantaged patients, foreigners, etc. (Diebolt et al., 1995; Lebas, 1995). 
It should be noted that there is no difference between, on the one hand, innovations fuelling a pure 'service' trajectory driven by the intensive organising principle and, on the other hand, the addition of a 'pure' constituent service within the framework of the extensive model of innovation. In other words, there is no difference between the strengthening of one (or two) column(s) $\left(\mathrm{C}(\mathrm{Y})\right.$ ) and the addition of a row $\mathrm{S}_{\mathrm{i}}$. Given the nature of our functional breakdown, which separates internal components from external functions, a pure service represented heuristically by the relationship $\mathrm{C}(\mathrm{Y})$ is identical to an $\mathrm{S}_{\mathrm{i}}$ with no technological content.

\section{4 .5 A relational trajectory?}

The 'contactual service' element of hospital output also has its own innovation dynamic. This innovation dynamic (or trajectory) describes the introduction of contactual service functions or characteristics or new ways of bringing together customers and service providers, as well as their evolution over time. In analytical terms, this trajectory (if its existence is accepted in principle) marks a break with the previous four. After all, the customer/user interface or contactual service operations can evolve by mobilising competences alone or material, information or knowledge processing technologies. It is difficult, therefore, to separate the relational trajectory from the pure service trajectory and from the material, informational or methodological trajectories.

Thus an experimental reception unit for foreigners also falls within the scope of a relational trajectory. The same applies to the introduction of mobile psychiatric emergency services or even the establishment of experimental administrative units in nursing departments with a view to providing comprehensive patient reception services (cf. Ponchon, 1999). All attempts to increase customer/patient loyalty (particularly in private hospitals) fall within the scope of both methodological and relational trajectories. Innovations in internal and external systems for transporting equipment and people (self-propelling vehicles, wheelchairs, robots, etc.) probably fall within the scope of both material and relational trajectories. The experiments with interactive communication and payment stations that many hospitals have conducted (Argacha, 1991; Viguier, 1994; Viguier et al., 1994) seem to us to fall within the scope of this relational trajectory; at the same time, in view of the technologies they mobilise, they also contribute to the informational trajectory.

The various strategies adopted to reduce waiting times fall within the scope of relational trajectories to the extent that they lead to great customer satisfaction. However, they rely on methods and a particular system of work organisation and so also fall within the scope of methodological trajectories.

\subsection{The combinatory principle}

Combinatory or architectural innovation constitutes the fourth organising principle driving innovation in hospitals. It is the one most commonly encountered. This organising principle, whose importance in the fields of micro-electronics and biotechnologies has been revealed in various studies (Henderson and Clark, 1990; Foray, 1994), plays an even more important role in service activities, particularly in services that are 'packages of packages', as is the case with hospitals. It encompasses 
all innovation mechanisms associated with the various principles outlined above (extensive, regressive and intensive). In other words, the combinatory model of innovation is based on the association and dissociation of constituent services and of the corresponding technologies and competences. It can also be at work at the organisational, intra-organisational and inter-organisational levels.

\subsubsection{The combinatory principle and the 'pure' principles}

As we have already said, the extensive, regressive and intensive models are ideal types. Since they are driven by pure (or basic) principles, it is not always easy to give (purified) examples. Nevertheless, they are valuable heuristic devices for understanding the diversity of forms of innovation in hospitals.

For its part, the combinatory model is the commonest and most concrete technical form or operational mode. After all, just like patients undergoing treatment, hospitals cannot (or should not) be 'sliced up'. Links and relationships exist everywhere, and they cannot be severed without impoverishing the analysis. In other words, the idealtypical models outlined above (the extensive, regressive and intensive principles) should not be mobilised in support of a fragmented concept of hospitals and innovation in hospitals. The combinatory principle draws on the 'pure' basic mechanisms outlined above and links them in a number of different ways. Thus the combinatory principle manifests itself through the repeated and simultaneous implementation of the various 'pure' principles (cf. Figure 1):

- the addition and/or elimination (association and dissociation) of constituent services (action on the rows of the analytical table);

- technological intensification and/or its converse (action on the columns of the analytical table). This principle manifests itself in concrete terms in the same way, namely through the addition and/or elimination (association and/or dissociation) of technologies or competences. These mechanisms may be expressed within a given technological sphere or may draw on several spheres (columns).

\section{INSERT Figure 1 : The combinatory principle as the implementation (in multiple configurations) of 'pure' principles}

\subsubsection{The combinatory principle from an organisational and intra-organisational perspective}

In our framework for analysing hospital output (Table 1), this combinatory principle does not affect one particular row or column but rather several rows and/or columns, which it combines and/or separates in order to produce an innovation. In this sense, the innovation process is rather like a puzzle in which various squares in the grid are combined in order to obtain a new service. This principle is the most concrete and most frequently encountered operational or instrumental mode.

There are very many examples of innovations derived from this combinatory principle. The scope and complexity of the architectural or combinatory process can vary (i.e. it may cover a variable number of squares on the analytical table). Thus the creation of a new hospital (for example, the Jeanne de Flandre hospital in Lille) follows this combinatory principle and extends over a considerable area of the table 
(if not its entire area, since a completely new institution is, quite literally, being built). After all, a new hospital is a combination of constituent services $\left(\mathrm{S}_{\mathrm{i}}\right)$, of technologies $(\mathrm{M}, \mathrm{I}, \mathrm{K})$ and competences $\mathrm{C}$. Another example is the recent setting-up of highly automated, so-called digital hospitals, in which the use of paper is greatly reduced and fully integrated IT systems are a ubiquitous presence, with computer terminals even located at patients' bedsides.

However, the combinatory principle can express itself at other levels. Thus different technologies (columns in the table) and the corresponding trajectories can be combined in various ways. They can be used together, while remaining 'separate', in order to produce given service characteristics. In that case, the technological trajectories exist independently of each other. The combinatory principle manifests itself simply in independent coexistence within the same organisation or department. However, the corresponding technologies (columns in the table) and trajectories can also be combined. In this case, the combinatory principle manifests itself in the existence of a single technology resulting from the hybridisation of different technologies (and trajectories). There are very many examples of the hybridisation of logistical and material processing trajectories and logistical and information processing trajectories in hospitals. After all, microelectronics and computer technology have gradually permeated all material logistical operations, from medical instrumentation to transport systems for equipment or patients, which are already closely linked to the transmission of information and are likely to be even more closely linked in future.

The following can be cited as examples of hybrid medical technologies (that is technologies that combine NITCs with more traditional, material processing technologies): computer-aided diagnostics, medical supervision, automated diagnostic equipment, video surgery, which emerged at the beginning of the 1990s and can be defined as an extension of coelioscopy (originally developed for use in gynaecology) for abdominal operations (appendectomy, hysterectomy, etc.). Video surgery is a hybrid technology that combines robotics (the surgeon's hands are replaced by an instrument) and NICTs (the surgeon's eyes are replaced by a camera). Imaging (magnetic resonance imaging, scanography, video endoscopy and nuclear medicine, particularly scintigraphy) is often regarded as the medical technology that has benefited most from advances in information technology (signal processing), automatics and video technology.

\subsubsection{The combinatory principle from an inter-organisational perspective: networks}

Most experiments with network-type structures (community health networks, coordinated care networks, etc.) are based on the combinatory principle and in such cases the analytical perspective is obviously an inter-organisational one. After all, many (external) constituent services are added together to form such structures, and such accumulations of services are often associated with increases in the scope of innovation trajectories and the creation of multiple linkages between them. Such experiments are very diverse in terms of the number of actors involved, the nature of those actors, their objectives and the technologies mobilised.

Community health networks probably have their roots in the gerontology and HIV networks set up in the early 1980s that brought together doctors in private practice 
and those working in hospitals. Networks have also been established in other medical or medico-social areas, including diabetes, hepatitis $\mathrm{C}$, social exclusion and the perinatal period. These networks may be set up at the intersection of various sets of problems and issues. This is the case, for example, with networks engaged with issues around the perinatal period and social exclusion, such as the provision of care for pregnant drug addicts and their children.

These networks vary in their level of sophistication. They range from the simple joint acquisition of expensive equipment by several hospitals or agreements on the shared use of equipment such as scanners or MRI machines to more complex structures such as hospital mergers, cooperation between public and private structures, the takeover of one hospital by another or the establishment, within hospitals or close to them, of units intended to create links with generalists : geriatric units run by general practitioners and social workers from outside the hospital and walk-in treatment centres for minor emergencies operated and managed by doctors and nurses from outside the hospital.

The many and varied ways in which research is mobilised by patients' associations also fall within the scope of this combinatory principle, since they involve hospitals in inter-organisational activities (Rabeharisoa and Callon, 2004). Home-based treatment also falls within the scope of this organising principle, since it combines hospital and home by means of a certain number of technologies and methods (Mehlman and Youngner, 1991; Arras, 1999; Bentur, 2001).

\section{Conclusion}

Our framework for the analysis of hospital output (at the organisational, intraorganisational or inter-organisational level) makes it possible to capture the multiple forms of innovation encountered in hospitals. Innovation is not exclusive preserve of a particular function (or of the professionals attached to that function).

It is not manifested solely in spectacular forms of tangible technologies. Innovation not only encompasses the whole of the area mapped out in our analytical framework but can also modify the extent of that area, depending on the type of organising principle at work. The extensive principle leads to the addition of new constituent services, while the regressive principle leads to the elimination of one or more such service. The intensive principle involves an increase in the scope of or an improvement in a particular technological component of a hospital's output, while the combinatory principle, which is more frequently encountered, brings together these various principles to generate innovations by combining (associating and/or dissociating) different constituent services and/or different technologies.

We will conclude by noting that the analytical model developed here can be applied to other service activities. It can be extended to all services that are architectural in nature, that is those that can be defined as combinations of other goods and services. This is the case, for example, with the hotel industry, large-scale retailing, airlines, tourism, amusement parks, etc.

\section{Acknowledgements}


We gratefully acknowledge the support of the Department of Research, Evaluation and Statistics (DREES) of the French ministries of Social Affairs, Work and Solidarity and of Health, the Family and the Handicapped. An earlier version of this paper also benefited from comments by the participants in the $12^{\text {th }}$ International Conference of RESER, Manchester, 2002. We would finally like to thank for their valuable input the anonymous referees appointed by the journal.

\section{References}

Acker, F., 1995. L'informatisation des unités de soins et travail de formalisation de l'activité infirmière. Sciences Sociales et Santé, 13(3), September, 69-91.

Ahern, M., 1993. The softness of medical production and implications for specifying hospital outputs. Journal of Economic Behavior and Organization, 20, 281-294.

Andersen, J.G., Aydin, C.E., 1997. Evaluating the impact of health care information system. International Journal of Technology Assessement in Health Care, 13(2), 380-393.

Argacha, J. P., 1991. Borne interactive de communication, Gestions Hospitalières, 311, December, 910-912.

Arras, J.D. (ed.), 1995. Bringing the Hospital Home, John Hopkins University Press, Baltimore.

Arrow, K.J., 1963. Uncertainty and the Welfare Economics of Medecine Care. American Economic Review, LIII, 941-67.

Bartoli, A., Anaut, M., 1996. Les paradoxes du changement dans les hôpitaux publics : facteurs de pérennité ou de fragilité, in: Contandriopoulos, A.P., Souteyrand, Y. (Eds.), L’hôpital stratège. John Libbey Eurotext, Montrouge, pp. 179-199,.

Battista, R.N., 1989. Innovation diffusion of health related technologies : a conceptual framework. International Journal of Technology Assessement in Health Care, 5(2), 227-248.

Béjean, S., Gadreau, M., 1997. Concept de réseau et analyse des mutations récentes du système de santé. Revue d'Economie Industrielle, 81, 77-97.

Béjean, S., Gadreau, M., 1991. Quelle théories économiques pour l'hôpital ? Cahiers Lillois d'Economie et de Sociologie, 18, 26-40.

Bentur, N. 2001. Hospital at home : what is its place in the health system. Health Policy, 55, 71-79.

Berbain, X., Minvielle, E., 2001. Informatique et gestion des unités de soins. Sciences Sociales et Santé, 19(3) September, 77-106.

Bernardy-Arbuz, M.-A., Bannier, M.-F., 1994. La démarche qualité au service des Trans'comm. Gestions Hospitalières, 333, February, 98-101.

Billard, V., 2001. Le réseau comme réponse à une meilleure prise en charge des personnes âgées. Gestions Hospitalières, 404, March, 165-169.

Bonhomme, D., Astic, M.-R., Anhoury, P., Mazé, M.-C., Mercatello, A., 1994. Pour une dynamique de la gestion de la qualité et des risques à l'hôpital. Gestions Hospitalières, 334, March, 208-212.

Boullier, D., De Certaines, J., 1992. L'art du compromis socio-technique dans l'innovation hospitalière : le cas des systèmes de communication et d'archivage d'images médicales. Sciences Sociales et Santé, 10(3), September, 75-103.

Burke, D.E., Menachemi, N., 2004. Opening the black-box : measuring hospital information technology capability. Health Care Management Review, 29(3), JulySeptember, 210-217. 
Coffey, R.J. et al., 1991. An introduction to critical paths. Quality Management in Health Care, 1(1), 45-54.

Coleman, J.J., Katz, E., Menzel, H., 1966. Medical innovation : a diffusion study, Bobbs-Merril, Indianapolis.

Conrad, R.F., Strauss, R.P. 1983., A Multiple-Output Multiple Input Model of the Hospital Industry in North Carolina. Applied Economics, 15, 341-352.

Costargent, G., 2000. CHU et centres hospitaliers, des missions redéfinies: de l'hôpital pivot à l'hôpital en réseaux, in: Dalmasso, R., Romatet, J.-J. (Eds.), L'hôpital réformateur de l'hôpital, Eres, Paris, pp. 35-57.

Courbon, T.C., 1995. Recherche-action et conception évolutive des systèmes d'information: deux aspects d'une même démarche, Working papers, IAE of Paris.

Cubbin, J., Domberger, S., Meadowcroft, S., 1987. Competition tendering and efficiency : the case of hospital cleaning. Fiscal Studies, 8(3), 49-58.

De Kervasdoué, J., Lacronique, J-F., 1981. L'état et la technique : l'apparition du rationnement, in: J. De Kervasdoué, J., Kimberly and V. Rodwin (Eds.), La santé rationnée : la fin d'un mirage, Economica, Paris, pp. 89-116.

Delande, G., 1999. Filières et réseaux en santé. Gestions hospitalières, 391, December, 746-755.

Dent, M., 1996. Professions, Information Technology and Management in Hospitals, Avebury, London.

Diebolt, J.M., Deloche, A., Willi, J., 1995. La cellule « accueil étrangers » de l'hôpital Broussais. Techniques Hospitalières, 595, April, 61-64.

Dixon, D.R., 1999. The behavioral side of information. International Journal of Medical Informatics, December, 56(1-3), 117-123.

Djellal, F., 2000. The Rise of Information Technologies in "Non-informational» Services. Vierteljahrshefte zur Wirtschaftsforschung, 4-69, 646-656.

Djellal, F., 2002. Le secteur du nettoyage face aux nouvelles technologies. Formation Emploi, 77, 37-49.

Djellal, F., Gallouj C., F. and K., 2004. L'hôpital innovateur : de l'innovation médicale à l'innovation de services, Masson, Paris.

Eddy, D., 1990. Screening for cervical cancer. Annals of Internal Medecine, 113, 214226.

England, I., Stewart, D., Walker, S. 2000. Information technology adoption in health care : when organisations and technology collide. Australian Health Review, 23(3), 176-185.

Evans, R., 1986. Finding the Levers, Finding the Courage : Lessons from CostContainment in North America. Journal of Health Politics, Policy and Law, 11, 585-616.

Foray, D., 1994. Les nouveaux paradigmes de l'apprentissage technologique. Revue d'Economie Industrielle, 69, (3), 93-104.

Fuchs, V., 1990. The Health Sector's Share of the Gross National Product. Science, 247, 534-538.

Fuchs, V., 1996. Economics, values and health care reform. The American Economic Review, 86, 1-24.

Gadrey, J., 1991. Le service n'est pas un produit: quelques implications pour l'analyse économique et pour la gestion. Politiques et Management Public, 9(1), 124.

Gadrey, J., 1996. L'économie des services, Repères, $2^{\text {nd }}$ ed. La découverte, Paris. 
Gadrey, J., 2000. The Characterization of Goods and Services: an Alternative Approach. The Review of Income and Wealth, 46(3), September, 369-387.

Gallouj, C., 1997. L'innovation dans le grand commerce, Report for European Commission, DG XII, TSER Programme.

Gallouj, C., Gallouj, F., 1996. L'innovation dans les services, Economica, Paris.

Gallouj, F., 1999. Les trajectoires d'innovation dans les services : vers un enrichissement des taxonomies évolutionnistes. Economies et Sociétés, 1, 143-169.

Gallouj, F., 2002. Innovation in the Service Economy: the New Wealth of Nations, Edward Elgar Publishers, Cheltenham, UK, Northampton MA, USA.

Gallouj, F., Weinstein, O., 1997. Innovation in services. Research Policy, 26, 537556.

Gallouj, F.,1994. Economie de l'innovation dans les services, L'Harmattan, Paris.

Gestions Hospitalières, 1994. Le prix de l'innovation hospitalière 1994, 334, March.

Gilibert, P., Fabretti, A.-M., 1998. Le centre de traitement et de régulation des appels d'urgence de Haute-Savoie. Gestions Hospitalières, 378, August-September, 577581.

Griffin-Cohen, M., 2001, Do comparisons between hospital support workers and hospitality workers make sense ? Report for Hospital Employee's Union, Canada, October, mimeo.

Groenewegen, P.P., Hutten, J.B. 1999. Improving primary health care through technological innovation. Health Policy, 13(3), 199-211.

Hatchuel, A., 1994. Apprentissage collectif et activités de conception. Revue française de gestion, 99, June-July-August, 109-120.

Hebert, M.A., 1998. Impact of IT on health care professionals : changes in work and the productivity paradox, Health Service Management Review,11(2), May, 69-79.

Hémidy, L., 1996. L'informatisation des hôpitaux et ses enjeux. Revue Française de Gestion, 109, June-July-August, 125-136.

Henderson, R.M., Clark, K.B., 1990. Architectural Innovation : the Reconfiguration of Existing Product Technologies and the failure of Established Firms. Administrative Science Quarterly, 35(1), March, 9-30.

Herbst, K., Littlejohns, P., Rawlinson, J., Collinson, M., Wyatt, J.C., 1999. Evaluating computerized health information systems : hardware, software and human ware. Journal of Public Health Medecine, 21(3), September, 305-310.

Hill, T.P., 1977. On Goods and Services. The Review of Income and Wealth, 4-23, $315-338$.

Hill, T.P., 1999. Tangibles, Intangibles and Services : a New Taxonomy for the Classification of Output. Canadian Journal of Economics, 32 (2) April, 426-444.

Hoffman, P.A., 1993. Critical path method : an important tool for coordinating clinical care. Joint Commission Journal on Quality Improvement, 19(7), 235-246.

Jerome-D'Emilia, B., Begun, J.W., 2005. Diffusion of breest conserving surgery in medical communities, Social Science and Medecine, 60, 143-151.

Larcher, P., Poloméni, P., 2001. La santé en réseaux : objectifs et stratégie dans une collaboration ville-hôpital, Masson, Paris.

Lau, F., Penn, A., Wilson, D., Noeworthy, T., Vincet, D., Doze, S., 1998. The diffusion of an evidence-base disease guidance system for managing stroke. International Journal of Medical Informatics, 51, 107-116.

Le Berre, R., Barralon, J.L., Lepin, J.L., Saby, M., Vilain, M., 1992. L’hôpital prestataire de services. Revue Hospitalière de France, 5, September-October, 558561. 
Lebas, J., 1995. L'espace «Baudelaire» de l'hôpital Saint-Antoine (AP-HP). Techniques Hospitalières, 595, April, 58-61.

Lumsdon, K., Hagland, M., 1993. Mapping care. Hospital and Health Networks, 67(20), October, 34-40.

Mehlman, M. J. and Youngner, S. J. (Eds.), 1991. Delivering High technology Home care, Springer, New York.

Moatti, J. P., 1991. Ethique médicale, économie de la santé : les choix implicites. Annales des Mines, 22, June, 74-80.

Nelson, R., Winter, S., 1982. An Evolutionnary Theory of Economic Change, Belknap Harvard, Cambridge, Mass. and London.

Newhouse, J.P., 1970. Towards a theory of non profit institutions : an economic model of the hospital. American Economic Review, 60, 64-74.

Newhouse, J.P., 1992. Medical care costs : how much welfare loss ? Journal of Economic Perspectives, 6(3), 3-23.

Nystrom, P.C., Ramamurthy, K., Wilson, A., 2002. Organizational context, climate and innovativeness : adoption of imaging technology. Journal of Engineering and Technology Management, 19(3), 221-247.

Paraponaris, A., Moatti, J.-P., Mossé, P., Huard, P., 1997. Economie de l'innovation médicale : bilan et perspectives, in: J.C., Sailly, T., Lebrun (Eds.), Dix ans d'avancées en économie de la santé, Actes des XIXèmes journées des économistes de la santé français, Editions John Libbey Eurotext, Montrouge, pp. 225-233.

Perry, S., 1988. Technology assessement in health care : the US perspective, Health Policy, 9(3), 317-324.

Phelps, C., 1992. Health Economics, Harper-Collins Publishers Inc., New-York.

Piatecki, C., Ulmann, P., 1995. La micro-économie de la santé : bilan et perspectives. Revue d'économie financière, 34, 47-69.

Ponchon, F., 1999. Des antennes dans les services de soins. Gestions Hospitalières, 383, February, 96-98.

Rabeharisoa, V., Callon, M., 2004. The involvement of Patients in Research Activities Supported by the French Muscular Dystrophy Association, in: S. Jasanoff (Ed.) States of Knowledge : The Co-production of Science and Social Order, Routledge, London and New York, pp. 234-263.

Rigby, M., 1999. Health Informatics as a tool to improve quality in non-acute care : new opportunities and matching need for new evolution paradigm. International Journal of Medical Informatics, 56, 141-150.

Sachot, E., 1989. La productique entre à l'hôpital. Politique industrielle, Winter, 135141.

Sasaki, L., 2003. Hospital Offer unconventional services in hopes of attracting future patients. Hospital Quarterly, 6(3), Spring, 85-86.

Schrayer, S., 1995. Les technologies médicales : une industrie de la santé, Editions Pradel, Paris.

Schumpeter, J. 1934. The theory of economic Development, Harvard Univ. Press, Cambridge, MA.

Shephard, R.W., 1970. Theory of cost and production functions, Princeton University Press, Princeton.

Stanback, T., 1987. Computerization and the Transformation of Employment: Government, Hospitals and Universities, Westview Press, Boulder, Colorado.

Sundbo, J., 1996. Development of the service system in a manual service firm : a case study of the Danish ISS. Advances in Services Marketing and Management, 5, 169-191. 
Sundbo, J., 1998. The organisation of innovation in services, Roskilde University Press, Roskilde.

Swindley, D., Thompson, C., 1992. Hospital Retailing. The Service Industries Journal, 12(2), April, 210-219.

Teboul, J., 1999. Le temps des services, Les Editions d'Organisation, Paris.

Thomas, L., 1975. The lives of a Cell, Bantam Books, New-York.

Viguier, J.-M., 1994. L'implantation d'un système d'encaissement des recettes hospitalières par borne monétique. Gestions Hospitalières, 334, March, 199-202.

Viguier, J.-M., Marre, D., Lambea, M., 1994. Bornes automatiques de paiement: expérience d'encaissement au CHU de Toulouse. Revue Hospitalière de France, 4, July-August, 326-335.

Waissman, R., 1995. Interactions familiales et impact de la technologie dans la gestion d'une maladie chronique chez l'enfant. Sciences Sociales et Santé,13(1), March, 81-99.

Weisbrod, B., 1991. The Health Care Quadrilemna : an Essay on Technological Change, Insurance, Quality of Care, and Cost Containment. Journal of Economic Literature, 29, 523-552. 
Table 1: a functional breakdown of hospital output or service

\begin{tabular}{|c|c|c|c|c|c|c|}
\hline $\begin{array}{l}\text { Constituent } \\
\text { services }\end{array}$ & $\begin{array}{l}\text { Competences } \\
\text { mobilised }\end{array}$ & \multicolumn{4}{|c|}{$\begin{array}{l}\text { Service medium, corresponding operations or functions and associated } \\
\text { technologies }\end{array}$} & \multirow{2}{*}{\begin{tabular}{|c|}
$\begin{array}{c}\text { ('External') use, } \\
\text { final or service } \\
\text { characteristics or } \\
\text { functions }\end{array}$ \\
Y \\
Service \\
functions and \\
characteristics \\
(+ \\
corresponding \\
disciplines)
\end{tabular}} \\
\hline $\mathrm{S}_{\mathrm{i}}$ & $\begin{array}{c}\text { C } \\
\text { Competences } \\
\text { in (the use of ) } \\
\text { technologies or } \\
\text { competences } \\
\text { directly } \\
\text { mobilised }\end{array}$ & \begin{tabular}{l}
\multicolumn{1}{c}{ M } \\
'Material' \\
operations \\
$(+$ \\
corresponding \\
sciences and \\
technologies $)$
\end{tabular} & \begin{tabular}{|l}
\multicolumn{1}{c}{ I } \\
'Informational' \\
operations \\
$(+$ \\
corresponding \\
sciences and \\
technologies)
\end{tabular} & \begin{tabular}{l}
\multicolumn{1}{c}{ K } \\
'Methodological' \\
operations \\
$(+$ \\
corresponding \\
sciences and \\
technologies $)$
\end{tabular} & \begin{tabular}{|l|}
\multicolumn{1}{c}{$\mathrm{R}$} \\
Contactual or \\
relational \\
service \\
operations \\
(+ \\
corresponding \\
sciences and \\
technologies) \\
\end{tabular} & \\
\hline $\begin{array}{l}\mathrm{S}_{1}: \quad \text { Medical } \\
\text { treatment/nursing } \\
\text { care }\end{array}$ & & XXXXXXXXX & XXXXXXXXX & & & \\
\hline $\begin{array}{l}\mathrm{S}_{2}: \\
\text { Accommodation }\end{array}$ & & & & & & \\
\hline Maintenance & & & & & & \\
\hline Reception & & & & & & \\
\hline Transport & & & & & & \\
\hline $\begin{array}{l}\text { Management, } \\
\text { administration }\end{array}$ & & & & & & \\
\hline Catering & & & & & & \\
\hline Crèche & & & & & & \\
\hline Laundry & & & & & & \\
\hline Leisure & & & & & & \\
\hline Retail activities & & & & & & \\
\hline Funeral services & & & & & & \\
\hline $\begin{array}{l}\text { Cleaning, waste } \\
\text { processing }\end{array}$ & & & & & & \\
\hline Etc. & & & & & & \\
\hline
\end{tabular}

*The shaded area represents the main concerns of the literature devoted to innovation in hospitals

Table 2 : The inter-organisational level of analysis of hospital output

\begin{tabular}{|c|c|c|c|c|c|c|c|}
\hline \multirow{2}{*}{$\begin{array}{c}\text { Organisation } \\
\mathrm{O} \\
\end{array}$} & \multirow{2}{*}{$\begin{array}{c}\text { Constituent services } \\
\mathrm{S} \\
\end{array}$} & \multirow{2}{*}{$\begin{array}{c}\text { Competences } \\
\mathrm{C} \\
\end{array}$} & \multicolumn{4}{|c|}{$\begin{array}{l}\text { Service medium, corresponding } \\
\text { operations or functions and associated } \\
\text { technologies }\end{array}$} & \multirow{2}{*}{$\begin{array}{c}\text { utilities } \\
\mathrm{Y} \\
\end{array}$} \\
\hline & & & $\mathrm{M}$ & I & $\mathrm{K}$ & $\mathrm{R}$ & \\
\hline \multirow{4}{*}{$\begin{array}{c}\text { Organisation } 1 \\
\text { (reference hospital) }\end{array}$} & $\mathrm{S}_{1}$ & & & & & & \\
\hline & $\mathrm{S}_{2}$ & & & & & & \\
\hline & $\mathrm{S}_{3}$ & & & & & & \\
\hline & & & & & & & \\
\hline \multirow{4}{*}{$\begin{array}{l}\text { Organisation } 2 \\
\text { (other hospital) }\end{array}$} & $\mathrm{S}_{1}$ & & & & & & \\
\hline & $\mathrm{S}_{2}$ & & & & & & \\
\hline & $\mathrm{S}_{3}$ & & & & & & \\
\hline & - & & & & & & \\
\hline \multirow{4}{*}{$\begin{array}{l}\text { Organisation } 3 \\
\text { (private clinic) }\end{array}$} & $\mathrm{S}_{1}$ & & & & & & \\
\hline & $\mathrm{S}_{2}$ & & & & & & \\
\hline & $\mathrm{S}_{3}$ & & & & & & \\
\hline & & & & & & & \\
\hline \multirow{4}{*}{$\begin{array}{c}\text { Organisation } 4 \\
\text { (Doctor in private practice) }\end{array}$} & $\mathrm{S}_{1}$ & & & & & & \\
\hline & $\mathrm{S}_{2}$ & & & & & & \\
\hline & $\mathrm{S}_{3}$ & & & & & & \\
\hline & .. & & & & & & \\
\hline \multicolumn{8}{|l|}{$\begin{array}{l}\text { Organisation } 5 \\
\text { (municipality) }\end{array}$} \\
\hline \multicolumn{8}{|l|}{$\begin{array}{c}\text { Organisation } 6 \\
\text { (non-profit organisation) }\end{array}$} \\
\hline & & & & & & & \\
\hline
\end{tabular}


Figure 1 : The combinatory principle as the implementation (in multiple configurations) of 'pure' principles

\section{COMBINATORY PRINCIPLE OF INNOVATION}

Actions on constituent services $\left(\mathrm{S}_{\mathrm{i}}\right)$, i.e. on the rows of the analytical table

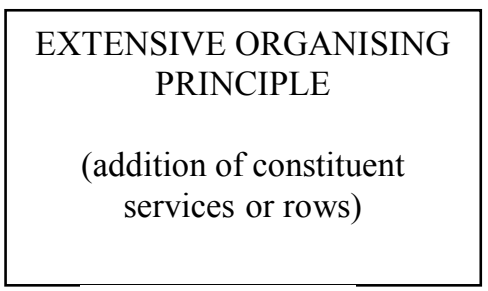

(Association)

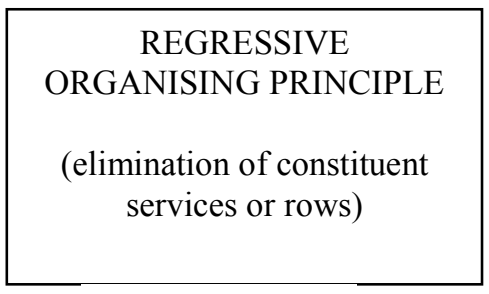

(Dissociation)

Actions on competences or technologies, i.e. on the columns of the analytical table

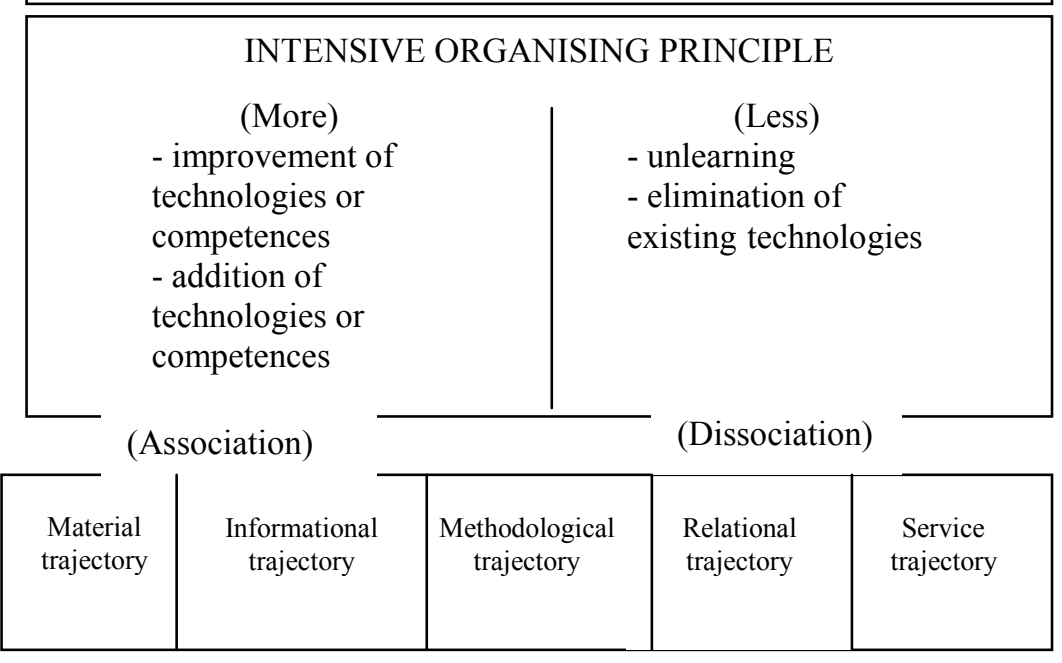

